\title{
Edukasi Etika Bisnis dan Investasi Syariah Bagi Pengelola dan Anak Asuh Yayasan Islamadina
}

\author{
Tony Seno Aji \\ Universitas Negeri Surabaya, tonyseno@unesa.ac.id \\ Yuyun Isbanah \\ Universitas Negeri Surabaya, yuyunisbanah@unesa.ac.id \\ Anang Kistyanto \\ Universitas Negeri Surabaya, anangkistyanto@unesa.ac.id \\ Andre Dwijanto Witjaksono \\ Universitas Negeri Surabaya, andredwijanto@unesa.ac.id \\ Budiono \\ Universitas Negeri Surabaya, budiono@unesa.ac.id
}

\begin{abstract}
The orphanage's foundation has largely begun to grow the business. This is a form of development of financial independence. Orphanages no longer fully expect funding from donors. In line with the above, the ability to manage ethical business and selection of sharia investment alternatives need to be understood by foundation managers and residents of orphanages. Training implementation methods using lecture, discussion, test, and simulation techniques. Training is carried out in two stages. The first stage of learning business ethics and sharia investment. The second stage is the simulation of investment instrument transactions. The target to be achieved is the acquisition of knowledge of managers / administrators and residents of orphanages related to business ethics and sharia investment instruments. Education of Business Ethics and Sharia Investment for the Managers and residents of Yayasan Islamadina was held on October 15, 2017. The activity was attended by 41 people. The results of the evaluation show that the level of satisfaction of the training and the ability of the resource persons are included in the high category. The results of the activities increased participants' understanding of business ethics and sharia investment instruments between before and after the training. This is demonstrated by the Wilcoxon Test results which show there are differences in pretest value with the posttest value, the conclusion there is increasing participants' understanding of the business ethics and sharia investment instruments between before training with after training
\end{abstract}

Keywords: Islamic Business Ethics, Sharia Investment, Investment Instrument 


\section{PENDAHULUAN}

\section{Analisis Situasi}

Yayasan Islamadina Surabaya terdiri dari Asrama panti asuhan putri dan asrama putra. Panti asuhan Islamadina merupakan salah satu panti asuhan yang ada di kelurahan Kandangan, Surabaya. Yayasan ini bertekat membentuk generasi penerus bangsa Indonesia untuk lebih baik dari generasi yang sudah ada saat ini tanpa membeda-bedakan aliran mapun golongan yaitu generasi yang berakhlak mulia dan luhur budi pekertinya. Islamadina tidak memiliki afiliasi dengan suatu paham atau golongan tertentu sehingga bisa diterima dan bermanfaat untuk semua pihak.

Saat ini Panti asuhan Islamadina memiliki 3 program utama yaitu Usaha mandiri budidaya jamur tiram, program wakaf, dan progam peduli Yatim Piyatu. Budidaya jamur tiram merupakan usaha yang bertujuan komersil dan memberi bekal keterampilan berwirausaha anak asuh agar mandiri. Program wakaf bertujuan untuk mendukung sarana kegiatan yayasan Islamadina dalam hal pengasuhan, pelatihan dan Pendidikan yang bersifat formal maupun nonformal. Sedangkan program Peduli Yatim Piyatu memiliki tujuan untuk membantu anak yatim, piyatu, yatim piatu dan kaum dhu'afa dalam bidang pendidikan yang tinggal di luar panti.
Berdasarkan data-data panti asuhan diketahui sebagian besar anak asuh pada panti asuhan tersebut adalah usia pra remaja dan remaja. Usia tersebut termasuk pada usia produktif dan diharapkan pada mereka ini mampu mengisi waktunya dengan kegiatan-kegiatan berharga yang bisa menambah pengetahuan dan keterampilan mereka. Pembinaan jiwa kewirausahaan sejak dini sangat perlu dilakukan guna mendukung kemandirian pada anak. Sejalan dengan hal tersebut, yayasan ini telah beberapa kali mendapat pelatihan terkait wirausaha.

Hasil identifikasi menunjukkan ada masalah yang dihadapi Yayasan Islamadina dan harus dicarikan solusi oleh pihak mitra, yaitu telah memiliki usaha/ bisnis, akan tetapi pemahaman terkait etika bisnis dan investasi syariah masih belum memadai. Selain itu pilihan alternatif investasi yang dilakukan masih sangat sederhana. Pihak Islamadina ingin terus mengembangkan aktivitas bisnis dan investasi dengan catatan tidak melanggar etika bisnis Islam.

Yayasan Islamadina kedepannya ingin mengembangkan yayasan yang tidak hanya berorientasi sosial, namun juga bisa mandiri dan mampu mengembangkan usaha bisnis dan investasi yang bersifat komersil. Yayasan Islamadina merupakan yayasan islam, sehingga dalam 
mengembangkan bisnis dan investasi sangat berhati-hati agar terhindar dari aktivitas yang melanggar norma dan etika agama Islam.

\section{Perumusan Masalah}

Hasil diskusi dengan pengelola yayasan Islamadina, diidentifikasi persoalan dan kebutuhan yang urgen untuk segera dipenuhi adalah adanya pemahaman terkait etika bisnis dan investasi syariah agar bisa terhindar dari aktivitas bisnis yang tidak sesuai dengan syariat Islam. Atas dasar persoalan tersebut, maka perlu adanya edukasi tentang etika bisnis dan investasi khususnya yang investasi syariah. Harapannya para pengurus dan anak-anak dalam mengelola bisnis yang sudah ada, menjadi seorang pebisnis yang beretika serta mampu menginvestasikan dana dari hasil bisnisnya sesuai dengan syariat Islam.

Pemateri dituntut lebih kreatif dalam melaksanakan proses edukasi, sehingga perolehan kompetensi pengelola panti asuhan dan anak-anak panti asuhan yang menjadi acuan keberhasilan pembelajaran dapat dicapai.

Jadi permasalahan pokok dalam PKM ini adalah "Bagaimana Edukasi Etika Bisnis dan Investasi Syariah Bagi Pengelola dan Anak Asuh Yayasan Islamadina?"

\section{Tujuan}

Tujuan dari pelaksanaan edukasi di yayasan Islamadina adalah diperolehnya pengetahuan dan pemahaman pengurus dan anak-anak panti asuhan dalam pemahaman bisnis etis dan instrument investasi syariah. Harapan kedepannya yayasan Islamadina bisa mengembangkan bisnis dan investasi yang etis dan berdasarkan prinsip-prinsip syariah.

\section{Manfaat}

Manfaat dari PKM ini adalah pengurus dan anak-anak panti asuhan dapat memahami etika bisnis dan berbagai instrument investasi syariah yang bisa digunakan dalam aktivitas bisnis dan investasi. Yayasan Islamadina bisa menerapkan etika bisnis dan investasi yang berdasarkan prinsip-prinsip syariah dalam pengembangan bisnis dan investasinya.

\section{KAJIAN TEORITIK}

\section{Etika Bisnis Islam}

Etika berasal dari kata "ethos" yang bermakna sikap, adat, kebiasaan, perasaan, cara berfikir, akhlak, watak dan kesusilaan. Jadi etika berarti norma, prinsip dan standar perilaku individu maupun kelompok yang membedakan benar dan salah (Nawatmi, 2010).

Bisnis di dalam Al-Quran disebut altijarah, sedangkan dalam bahasa arab 
tijaraha. Tijaraha berawal dari kata tajara, tajranwatijarata, yang memiliki arti berniaga. Dalam al-mufradat fi gharib alQuran, ar-Raghib al-Ashfahani menjelaskan makna at-Tijarah sebagai pengelolaan harta dengan tujuan mencari keuntungan. Bisnis dalam Islam pada hakekatnya mirip dengan bisnis pada umumnya, namun harus sesuai ajaran AlQuran, Al Hadist, Al-Ijma dan Ijtihad/Qiyas (Juliyani, 2016).

Velasquez (2005) menyatakan bahwa etika bisnis adalah studi yang difokuskan pada moral yang benar dan salah. Studi ini fokus pada standar moral yang digunakan dalam kebijakan, institusi, dan perilaku bisnis. Konsep ini penting untuk digunakan dalam setiap usaha demi menjaga hubungan dengan pelanggan. Disamping itu badan usaha/organisasi yang telah beroperasi juga harus mempertimbangkan keputusan investasi atas dana yang diperolehnya.

Terminologi pengertian etika dalam Islam ialah akhlak. Al- Qur'an memberi pentunjuk supaya dalam aktivitas bisnis tercipta hubungan harmonis, tidak ada unsur eksploitasi serta saling ridha (QS. An Nisa':29). Selain itu juga harus terbebas dari kecurigaan, penipuan, dan sebaiknya administrasi dalam transaksi kredit harus ada (QS.Al Baqarah:282) (Nawatmi, 2010).

Etika bisnis Islam merupakan akhlak dalam melakukan aktivitas bisnis yang didasarkan pada nilai-nilai Islam, sehingga kekhawatiran akan hilang dalam berbisnis (Juliyani, 2016). Dalam kaidah fikih, hukum kegiatan muamalah ialah mubah. Semua aktivitas dalam hubungan antar manusia diperbolehkan, kecuali aktivitas tersebut ada larangan yang jelas (Fathurrahman, 2012).

Aktivitas bisnis dalam Islam harus dilakukan berdasarkan aturan. Islam memberikan pedoman dan rambu-rambu dalam menjalankan usaha. Sudah semestinya pelaku bisnis muslim paham hukum serta aturan dalam Islam yang mengatur mu'amalah. Idealnya muslim yang baik juga dapat membedakan haram, halal, dan syubhat (Norvadewi, 2015).

\section{Investasi}

Tandelilin (2010) menjelaskan bahwa investasi adalah komitmen pada sejumlah dana atau sumber daya lainnya yang dilakukan sekarang, dengan maksud mendapatkan untung di waktu mendatang. Atas dasar hal tersebut penting kiranya suatu organisasi harus tepat dalam memilih alternatif instrument investasi.

Dalam Islam, Investasi merupakan salah satu kegiatan yang dianjurkan. Secara 
eksplisit terdapat dalam QS. Al-Baqarah: 261, Al-Nisa':9, Al-Hasyr:18, Lukman:34, dan lain sebagainya. Dalam Islam tidak semua investasi diperkenankan. Investor muslim hanya diperkenankan berinvestasi yang sesuai dengan ajaran Islam. Prinsipprinsip tersebut diantaranya meliputi jenis usaha, transaksi yang sesuai norma-norma syariah (Sakinah, 2014).

\section{MATERI DAN METODE}

\section{Kerangka Pemecahan Masalah}

Untuk memecahkan permasalahan di atas maka dilakukakan langkah-langkah sebagai berikut:

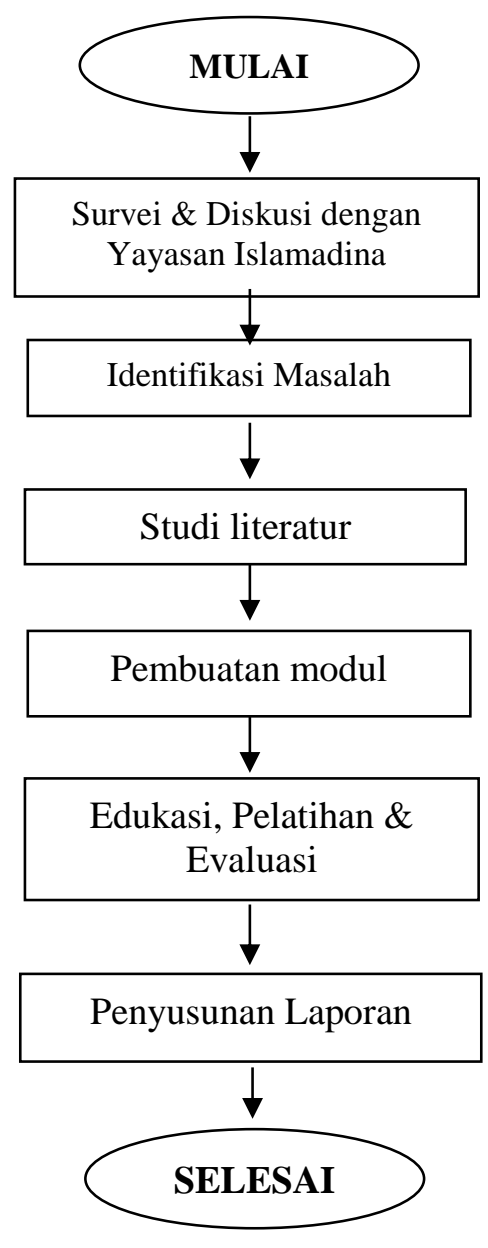

\section{Gambar 1. Kerangka Pemecahan Masalah}

\section{Realisasi Pemecahan Masalah}

Berbagai proses dalam kerangka pemecahan masalah (gambar 1) sudah dilakukan dengan baik dan pelaksanaan edukasi dan pelatihan sudah dilaksanakan pada tanggal 15 Oktober 2017.

\section{Khalayak Sasaran}

Khalayak sasaran dari pelaksanaan PKM adalah seluruh pengurus dan anak asuh Yasayasan Islamadina Surabaya. 


\section{Metode}

Metode pelaksanaan edukasi menggunakan teknik ceramah, diskusi, kerja kelompok, dan simulasi. Untuk melihat efektifitas proses edukasi etika bisnis dan investasi syariah dan pengembangan metode edukasi selanjutnya maka dilakukan action research.

Kegiatan dilaksanakan di Aula Yayasan Islamadina. Peserta edukasi adalah pengurus dan anak-anak yayasan Islamadina. Kegiatan dilaksanakan dalam 2 tahap. Tahap pertama pemahaman tentang etika bisnis dan tahap kedua adalah pengenalan dan edukasi tentang instrumen investasi, khususnya investasi syariah.

Dalam pelaksanaan kegiatan edukasi etika bisnis dan instrument investasi syariah, mitra turut berpartisipasi dalam bentuk dukungan non financial. Dukungan non financial yang diberikan mitra adalah komitmen dari mitra untuk berperan aktif dalam kegiatan edukasi.

\section{HASIL DAN PEMBAHASAN}

Edukasi Etika Bisnis dan Investasi Syariah bagi Pengelola dan Anak Asuh Yayasan Islamadina telah dilaksanakan. Adapun tahapan aktivitas yang sudah dilaksanakan dipaparkan di bawah ini:

\section{a. Persiapan kegiatan}

Tahap persiapan pertama dimulai dengan koordinasi tim terkait rencana dan timeline pelaksanaan pengabdian. Selanjutnya tim melakukan identifikasi masalah yang dimiliki oleh mitra. Permasalahan yang berhasil ditemukenali kemudian dirumuskan penyelesaiannya. Tim melakukan koordinasi dan penawaran kerjasama untuk menyelesaikan masalah yang dihadapi mitra. Di tahap ini terjadi kesepakatan kerjasama. Selanjutnya tim bersama mitra membuat schedule jadwal pelatihan dengan mempertimbangkan tingkat aktivitas masing-masing. Hasilnya disepakati bahwa pelatihan dilaksanakan pada hari minggu tanggal 15 Oktober 2017.

Tahap Kedua adalah koordinasi tim dalam melakukan penyusunan materi pelatihan (bahan ajar). Untuk memantapkan pemahaman mitra terkait instrument investasi, pada tahap kedua pelatihan peserta ditunjukkan contoh instrument investasi syariah.

Tahap akhir tim PKM menyusun soal pretest, posttest serta angket yang digunakan untuk mengetahui respon peserta atas pelaksanaan edukasi dan pelatihan. Angket respon peserta terdiri dari tingkat kepuasan pelaksanaan pelatihan (instrument pertanyaan meliputi: tema pelatihan, ketepatan waktu, kelengkapan 
materi, suasana pelatihan,sarana, pra sarana, dan pelayanan panitia) dan kemampuan narasumber (instrument pertanyaan meliputi: penguasaan materi, cara penyajian materi, manfaat materi, interaksi dengan peserta, dan media yang digunakan.

\section{b. Pelaksanaan Kegiatan}

Pelaksanaan kegiatan PKM pada tanggal 15 Oktober 2017. Lokasi pengabdian di aula Yayasan Islamadina Wisma Tengger II/ 8 Surabaya. Data peserta yang mengikuti pelatihan sebanyak 41 orang, dengan karakteristik demografi sebagai berikut:

Tabel 1. Karakteristik Demografi Peserta Pelatihan

\begin{tabular}{|c|c|}
\hline $\begin{array}{c}\text { Karakteristik } \\
\text { Demografi }\end{array}$ & Jumlah Peserta \\
\hline Jenis Kelamin & $\begin{array}{l}\text { - laki-laki } 25 \text { orang } \\
\text { - perempuan } 16 \text { orang }\end{array}$ \\
\hline Usia & 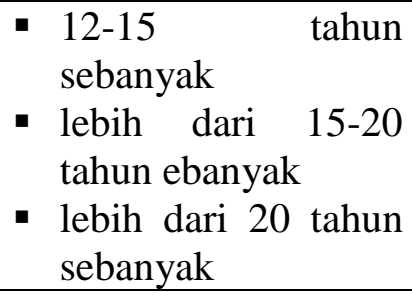 \\
\hline $\begin{array}{l}\text { Tingkat } \\
\text { pendidikan }\end{array}$ & $\begin{array}{l}\text { - SMP/sederajat } \\
\text { sebanyak } 18 \text { orang } \\
\text { - SMA/sederajat } \\
\text { sebanyak } 20 \text { orang } \\
\text { - } \begin{array}{l}\text { Perguruan tinggi } \\
\text { sebanyak } 3 \text { orang }\end{array}\end{array}$ \\
\hline
\end{tabular}

Sumber: data diolah

Mengikuti permintaan mitra, dalam pelaksanaannya kegiatan PKM ini tidak hanya memberikan materi terkait dengan etika bisnis dan investasi syariah, tetapi juga memberikan pelatihan ketrampilan yaitu membuat kerajinan tas rajut khusus untuk remaja putri.

Tingkat keberhasilan kegiatan diukur dengan menggunakan dua indikator. Pertama menggunakan lembar evaluasi peserta untuk mengukur tingkat kepuasan pelatihan. Kedua menggunakan instrument pertanyaan (soal) berupa soal pretest dan soal posttest untuk mengukur tingkat pemahaman (hasil belajar) peserta pelatihan.

\section{c. Hasil dan Evaluasi Kegiatan}

Evaluasi pelaksanaan pelatihan diukur menggunakan instrument pertanyaan yang terdiri dari dua indikator, yaitu kepuasan pelaksanaan pelatihan dan kemampuan narasumber. Skala likert digunakan dalam mengukur tingkat kepuasan pelaksanaan pelatihan dan kemampuan narasumber dalam 5 kategori dengan skor berkisar 1 s.d. 5. Dengan menggunakan kriteria tiga kotak (Three Box Method), maka diperoleh rentang sebesar 1,33 dengan kriteria rendah, sedang dan tinggi.

Tabel 2. Three Box Method

\begin{tabular}{cc} 
Skor & Kriteria \\
\hline $1,00-2,33$ & Rendah \\
\hline $2,34-3,67$ & Sedang \\
\hline $3,68-5,00$ & Tinggi \\
\hline
\end{tabular}


Sumber: data diolah

\section{c.1) Kepuasan pelaksanaan pelatihan}

Pengukuran kepuasan pelaksanaan pelatihan menggunakan enam instrument pertanyaan,yaitu tentang tema pelatihan, ketepatan waktu, kualitas materi, suasana pelatihan, sarana prasarana, dan pelayanan panitia. Hasil pengolahan data menujukkan bahwa secara umum peserta merasa puas terhadap pelaksanaan pelatihan. Hasil ini dapat ditunjukkan dalam tabel berikut:

Tabel 3. Hasil pengukuran kepuasan pelatihan

\begin{tabular}{|c|c|c|}
\hline $\begin{array}{l}\text { Instrumen } \\
\text { pertanyaan }\end{array}$ & $\begin{array}{l}\text { Mean } \\
\text { Item }\end{array}$ & $\begin{array}{c}\text { Mean } \\
\text { Indikator }\end{array}$ \\
\hline Tema pelatihan & 4,05 & \multirow{6}{*}{$\begin{array}{c}3,83 \\
\text { (tinggi) }\end{array}$} \\
\hline Ketepatan waktu & 3,51 & \\
\hline Kelengkapan materi & 3,83 & \\
\hline Suasana pelatihan & 3,71 & \\
\hline Sarana pra sarana & 3,80 & \\
\hline Pelayanan panitia & 4,04 & \\
\hline
\end{tabular}

Tabel 3 merupakan jawaban peserta tentang hasil pengukuran kepuasan pelaksanaan pelatihan. Berdasarkan tabel di atas, tingkat kepuasan pelaksanaan pelatihan berada di range 3,68-5,00 dan mean sebesar 3,83, artinya termasuk dalam kategori yang tinggi.

\section{c.2) Kemampuan narasumber}

Pengukuran persepsi peserta pelatihan terkait kemampuan narasumber dalam menyampaikan materi pelatihan menggunakan lima instrument pertanyaan yaitu: penguasaan materi, cara penyajian materi, manfaat materi, interaksi dengan peserta, dan media yang digunakan. Hasil pengukuran dirangkum dalam tabel berikut:

Tabel 4. Persepsi Peserta Terhadap Kemampuan Narasumber

\begin{tabular}{|c|c|c|}
\hline $\begin{array}{l}\text { Instrumen } \\
\text { pertanyaan }\end{array}$ & $\begin{array}{c}\text { Mean } \\
\text { Item }\end{array}$ & $\begin{array}{c}\text { Mean } \\
\text { Indikator }\end{array}$ \\
\hline $\begin{array}{l}\text { Penguasaan } \\
\text { materi }\end{array}$ & 4 & \multirow{5}{*}{$\begin{array}{c}4,16 \\
\text { (tinggi) }\end{array}$} \\
\hline $\begin{array}{l}\text { Cara penyajian } \\
\text { materi }\end{array}$ & 4,19 & \\
\hline Manfaat materi & 4,49 & \\
\hline $\begin{array}{l}\text { Interaksi dengan } \\
\text { peserta }\end{array}$ & 4,10 & \\
\hline $\begin{array}{ll}\text { Media } & \text { yang } \\
\text { digunakan } & \end{array}$ & 4,02 & \\
\hline
\end{tabular}

Tabel 4 merupakan persepsi peserta pelatihan tentang kemampuan narasumber. Berdasarkan tabel di atas, berada di range 3,68-5,00 dengan total mean sebesar 4,16. Jadi menurut peserta kemampuan narasumber dalam memaparkan materi pelatihan termasuk dalam kategori yang tinggi karena berada pada range 3,68-5,00 dengan total mean variabel sebesar 4,16.

\section{d. Pembahasan}

Penilaian tingkat efektivitas dan keberhasilan pelatihan salah satunya diukur dengan menggunakan pengujian 
kemampuan antara sebelum dan sesudah pelatihan. Peserta diminta mengerjakan soal pretest sebelum materi pelatihan diberikan dan posttest setelah materi. Hasil pretest dan post test diperoleh data nilai peserta yang selanjutnya akan dilakukan uji beda (uji t) menggunakan software SPSS. Uji beda mengunakan paired sample test (variabel yang berhubungan). Uji $\mathrm{t}$ berpasangan digunakan karena data yang diperoleh tidak bebas atau berpasangan. Dari 41 peserta yang hadir dalam pelatihan diperoleh data 38 peserta yang mengikuti pretest, sehingga data itu yang digunakan untuk sampel.

Data yang akan di uji beda (uji t) sebelumnya dilakukan uji normalitas untuk melihat data berdistribusi normal. Uji normalitas yang digunakan ialah Kolmogorov-Smirnov serta Shapori-Wilk dengan SPSS. Adapun hasil uji normalitas adalah sebagai berikut:

Tabel 5 Uji Normalitas

\begin{tabular}{lcccc}
\hline & \multicolumn{2}{c}{ K-S $^{\mathrm{a}}$} & \multicolumn{2}{c}{ S-W } \\
\hline & Stat. & Sign. & Stat. & Sign. \\
\hline Pretest & .125 & .140 & .957 & .147 \\
\hline Posttest & .200 & .001 & .910 & .005 \\
\hline
\end{tabular}

a. Lilliefors Significance

Sumber: data diolah

Berdasarkan tabel 5 , uji normalitas dengan menggunakan Kolmogorov-
Sminov dan Shapiro-Wilk diketahui bahwa data berdistribusi tidak normal yang ditunjukkan oleh angka signifikansi lebih kecil dari 0.05. Oleh sebab itu data tidak memenuhi syarat untuk dilakukan pengujian statistik parametrik khususnya uji paired sample t test. Sebagai alternatif agar data masih bisa di uji atau dianalisis, dengan menggunakan metode statistik non parametrik yaitu uji Wilcoxon. Uji Wilcoxon bisa digunakan untuk mengetahui perbedaan rata-rata dua sampel yang berpasangan.

Tabel 6 Uji Wilcoxon

\begin{tabular}{|c|c|c|c|}
\hline Posttest - Pretest & $\mathrm{N}$ & $\begin{array}{l}\text { Mean } \\
\text { Rank }\end{array}$ & $\begin{array}{l}\text { Sum of } \\
\text { Ranks }\end{array}$ \\
\hline Negative Ranks & $0^{\mathrm{a}}$ & .00 & .00 \\
\hline Positive Ranks & $32^{b}$ & 16.50 & 528.00 \\
\hline Ties & $6^{c}$ & & \\
\hline Total & 38 & & \\
\hline $\begin{array}{l}\text { a. Posttest }<\text { Pretest } \\
\text { b. } \text { Posttest }>\text { Pretest } \\
\text { c. Posttest }=\text { Pretest } \\
\text { Sumber }: \text { data, diolah }\end{array}$ & & & \\
\hline
\end{tabular}

Tabel 6 di atas menjelaskan bahwa: negative range atau selisih (negatif) antara nilai pre test dan post test adalah nol, untuk nilai $\mathrm{N}$, mean rank, maupun sum of range. Angka nol ini menunjukkan tidak ada penurunan nilai pre test menuju nilai post test.

Positive range (selisih positif) pemahaman peserta terkait materi etika 
bisnis dan instrument investasi syariah untuk pretest dan posttest. Terdapat 32 data positif $(\mathrm{N})$, maknanya ke 32 peserta terjadi kenaikan nilai pre test ke nilai post test. Mean Range atau rata-rata kenaikan tersebut sebesar 16.50, sedangkan jumlah rangking positif / Sum of Range sebesar 528.00

Makna Ties ialah kesamaan antara nilai pre test dan post test. Berdasarkan hasil pengujian diketahui bahwa terdapat 6 peserta yang memiliki kesamaan nilai pre test dan post test

Hasil pengujian diperoleh output "test statistic" sebagai berikut:

\section{Tabel 7. Test Statistics ${ }^{\mathrm{b}}$}

\begin{tabular}{lr}
\hline & Post test-Pre test \\
\hline$Z$ & $-4.946^{a}$ \\
\hline Asymp. Sig. (2-tailed) & .000 \\
\hline a. Based on negative ranks. \\
b. Wilcoxon Signed Ranks Test \\
Sumber: data, diolah
\end{tabular}

Dasar yang digunakan untuk pengambilan keputusan dalam $\mathrm{Uji}$ Wilcoxon adalah:

1. Seandainya nilai Asymp.Sig (2-tailed) lebih kecil dari 0.05 , maka Ha diterima 2. Seandainya nilai Asymp.Sig (2-tailed) lebih besar dari 0.05 , maka Ha ditolak

Dari tabel 7 "test statistic", diperoleh nilai Asymp.Sig (2-tailed) sebesar 0.000.
Nilai 0.000 lebih kecil dibandingkan 0.05, oleh karena itu bisa disimpulkan $\mathrm{Ha}$ diterima. Berarti terdapat beda antara nilai pre test dengan nilai post test. Dapat diambil kesimpulan bahwa ada peningkatan pemahaman peserta terkait materi etika bisnis dan instrument investasi syariah antara sebelum pelatihan dengan sesudah pelatihan.

Setelah dilakukan pelatihan, peserta pelatihan di yayasan Islamadina akhirnya memahami pandangan islam dalam bisnis dan investasi, etika investor dalam berinvestasi, instrumen-instrumen investasi yang sesuai syariah islam. Produk-produk bank syariah dan bisa memilih investasi yang sesuai syariah islam

Masih banyak umat muslim yang belum memahami etika bisnis islam dalam melakukan bisnisnya, diantaranya penelitian dari Hulaimi (2017). Islam merupakan way of life yang tidak bisa dinafikkan lagi, sebab Islam merupakan ajaran yang universal dan lengkap dengan aturan aplikatif dan jelas. Semua sisi kehidupan manusia diatur dalam Islam, khususnya dalam aktivitas bisnis. Namun, etika bisnis belum diterapkan oleh kebanyakan umat Islam dan perusahaan dalam aktivitas bisnisnya, oleh sebab itu terjadi persaingan yang tidak seimbang 
antara pemodal lemah dan pemodal kuat. Ada banyak ketidakadilan, penyuapan, munculnya moral hazard, dan lain-lain. Oleh sebab itu perlu adanya integrasi etika Islam ke dalam aktivitas bisnis.

Penelitian sebelumnya ada yang menunjukkan bahwa terdapat pengaruh positif antara etika bisnis dengan kinerja perusahaan. Oleh karena itu, sangat penting bagi dunia bisnis khususnya yang beragama Islam, untuk menerapkan nilainilai Islam dalam aktivitas bisnis. Apalagi fakta sejarah menyatakan Nabi Muhamad sebagai pedagang sukses. Nabi merupakan pedagang yang jujur dan selalu menggunakan etika bisnis Islam dalam setiap aktivitas bisnisnya (Nawatmi, 2010).

Investasi sangat dianjurkan dalam Islam. Hal ini secara tersirat bisa dilihat dari perintah untuk membayar zakat bagi orang yang punya aset yang tidak produktif (idle asset). Asset yang dikelola secara produktif tidak dikenai kewajiban zakat dan zakat hanya akan dipungut dari hasil yang didapat dari investasi tersebut (Hayati, 2016).

\section{KESIMPULAN DAN SARAN}

\section{Kesimpulan}

Edukasi Etika Bisnis dan Investasi Syariah bagi Pengelola dan Anak Asuh
Yayasan Islamadina dilaksanakan pada tanggal 15 Oktober 2017. Kegiatan diikuti oleh 41 orang. Hasil evaluasi menunjukkan bahwa tingkat kepuasan pelaksanaan pelatihan dan kemampuan narasumber termasuk dalam kategori tinggi. Hasil kegiatan terjadi peningkatan pemahaman peserta tentang etika bisnis dan instrument investasi syariah antara sebelum dan sesudah pelatihan. Hal ini ditunjukkan oleh hasil Uji Wilcoxon Test yang menunjukkan bahwa ada perbedaan antara nilai pretest dan nilai posttest, sehingga dapat disimpulkan pula bahwa terdapat peningkatan pemahaman peserta terkait materi etika bisnis dan instrument investasi syariah antara sebelum pelatihan dengan sesudah pelatihan.

\section{Saran}

1. Untuk menyelenggarakan kegiatan serupa lebih efektif jika alokasi waktu ditambah. Sehingga pemahaman peserta menjadi lebih baik.

2. Perlu diadakan pelatihan lanjutan khususnya tentang praktik/simulasi transaksi. Pelatihan lanjutan ini akan sangat membantu para peserta yang berkeinginan untuk memahami lebih detail terkait seluruh instrumen dan tatacara transaksi. 
Fathurrahman, A. (2012). Model Investasi Alternatif: Sebuah Studi Komparatif antara Konvensional dan Islam. UNISIA , XXXIV(77), 149-157. https://doi.org/https://doi.org/10.2088 5/unisia.vol34.iss77.art3

Hayati, M. (2016). Investasi menurut Perspektif Ekonomi Islam. Journal of Islamic Economics and Business, 1(1), 66-78.

https://doi.org/http://dx.doi.org/10.24 042/febi.v1i1.143

Hulaimi, A. (2017). Etika Bisnis Islam dan Dampaknya terhadap Kesejahteraan Pedagang Sapi. Jurnal Ekonomi Dan Bisnis Islam, 2(1), 17-31. Retrieved from

http://journal.febi.uinib.ac.id/index.ph $\mathrm{p} / \mathrm{jebi} /$ article/view/64/pdf

Juliyani, E. (2016). Etika Bisnis dalam Persepektif Islam. Jurnal Ummul Qura, VII(1), 63-74.

Nawatmi, S. (2010). Etika Bisnis dalam Perspektif Islam. Fokus Ekonomi (FE), 9(1), 5058.

Norvadewi. (2015). Bisnis dalam Perspektif Islam (Telaah Konsep, Prinsip, dan Landasan Normatif). AlTijary, 1(1), 33-46.

Sakinah. (2014). Investasi dalam Islam. Iqtishadia Al-Ihkâm, 1(2), 14. https://doi.org/10.19105/iqtishadia.v1 i2.483

Tandelilin, E. (2010). Portfolio dan Investasi, Teori dan Aplikasi (Pertama). Yogyakarta: Kanisius.

Velasquez, M. G. (2005). Etika Bisnis, Konsep dan Kasus (5th ed.). 